\title{
AS FUNÇÕES DO MANUAL CIENTÍFICO NA ESTRUTURA DAS REVOLUÇÕES CIENTÍFICAS
}

\author{
THE FUNCTIONS OF THE SCIENCE TEXTBOOK IN THE STRUCTURE OF SCIENTIFIC REVOLUTIONS
}

Adilson Koslowski*

\begin{abstract}
RESUMO
O objetivo deste artigo é procurar verificar as várias funções da literatura científica, especialmente o uso do manual científico no ensino e na aprendizagem da ciência como sustentado na Estrutura das revoluções científicas. Thomas S. Kuhn faz várias observações sobre o uso e as funções do manual científico na famosa obra. O objetivo é agrupar e sintetizar sua posição sobre o assunto. Pretende-se realizar algo semelhante ao famoso texto de Margaret Masterman em "A natureza de um paradigma", quando encontrou vinte e uma definições de paradigma; nosso objetivo é numerar e descrever as dezesseis funções do manual encontradas no texto. Posteriormente, analisa-se a crítica feita por Harvey Siegel à posição kuhniana a respeito dessa temática em "Kuhn and Schwab on Science Texts and the Goals of Science Education" e Rationality Reddemed? Further Dailogues on an Education Ideal. Siegel não concorda com a posição de Kuhn e para rebatê-lo utiliza-se dos estudos do educador Joseph J. Schwab, The Teaching of Science as Enquiry, cujos estudos focaram na articulação da filosofia da educação, da ciência e do currículo.
\end{abstract}

PALAVRAS-CHAVE: manual científico; Thomas Kuhn; Harvey Siegel; Joseph J. Schwab; ensino e aprendizagem da ciência.

\section{ABSTRACT}

The aim of this article is to seek to verify the various functions of the scientific literature, especially the use of the textbook in the teaching and learning of Science as supported by the Structure Of Scientific Revolution. Thomas S. Kuhn makes several observations about the use and functions of the textbook in the famous work. The objective is to group and sumarize his positon on the subject. It is intended to accomplish something similar to Margaret Masterman's famous text in "The nature of a paradigm" when he found twenty-one definitions of paradigm, our goal is to number and describe the sixteen manual functions found in the text Subsequently, Harvey Siegel's criticism of the kuhnian position on this thema is analyzed in "Kuhn and Schwab on Science Texts and the Goals of Science Education" and Rationality Reddemed? Further Dailogues on an Education Ideal. Siegel does not agree with kuhn's position and to refute it he uses the studies of the educator Joseph J. Scwab, The Teaching of Science as Enquiry, whose studies focused on the articulation of the Philosophy of Education, Science and Curriculum.

KEYWORDS: textbook; Thomas Kuhn; Harvey Siegel; Joseph J. Schwab; science teaching and learning.

\footnotetext{
*Doutor em Filosofia. Professor de Filosofia no Departamento da UFS. E-mail: adilsonkoslowski@ yahoo.com.br.
} 


\section{INTRODUÇÃO}

Os manuais científicos são um instrumento didático importante no ensino e na aprendizagem das disciplinas científicas. Um filósofo que se interessou pelas funções do manual é, sem dúvida, Thomas Kuhn (1922-1996). Há várias passagens sobre o manual e as suas funções, bem como limites, na obra A estrutura das revoluções científicas (1962). Kuhn dedicou bastante espaço, comparado com outros filósofos da ciência, para investigar as funções dos manuais científicos e a influência na concepção de ciência, que implicitamente são sustentadas nos manuais ${ }^{1}$. Também encontramos o manual como objeto de investigação nas ciências da educação científica ${ }^{2}$. Outros campos de estudo do manual científico são verificados na sociologia do conhecimento e nos estudos de gênero ${ }^{3}$.

O objetivo deste artigo é evidenciar as funções do manual científico, como exposto na famosa obra A estrutura das revoluções científicas (1962). Pretende-se realizar algo semelhante ao famoso texto de Margaret Masterman em "A natureza de um paradigma" (LAKATOS; MUSGRAVE, 1979, p. 63-71), quando encontrou vinte e uma definições de paradigma; nosso objetivo são as funções do manual. Mesmo passados quase sessenta anos, ninguém o fez. Depois dessa reconstrução da posição de Kuhn, passa-se a uma das primeiras críticas feitas à posição kuhniana a respeito dessa temática por Harvey Siegel.

Estrutura-se este artigo em três partes. Na primeira, faz-se breve apresentação sobre os gêneros científicos, estabelecendo o manual como um desses gêneros. Na segunda parte, é

\footnotetext{
${ }^{1}$ Um dos pioneiros em considerar a importância do manual para a compreensão da ciência foi Ludwik Fleck (18961961) na famosa obra Gênese e desenvolvimento de um fato científico, de 1935. Para Fleck (2009), o "estilo de pensamento" de uma comunidade científica pode ser descoberto pelo estudo comparativo dos manuais. Essa obra influenciou o pensamento de Kuhn, cuja influência ele afirmou no Prefácio da Estrutura das Revoluções Científicas (1975, p. 11) e no Prefácio ao livro de Fleck na versão inglesa de 1976.

${ }^{2}$ Tomo como exemplo o livro How we Teach Science (2019), de John L. Rudolph. Ele faz uma reconstrução histórico-crítica do ensino da ciência nos últimos 130 anos nos EUA. A problemática é como ensinar ciências nas escolas. Antes dos anos 1800, a ciência é ensinada como aprender fatos e como isso torna possível fazer coisas. A ciência é algo útil e, por isso, deve ser ensinada. Com a vinda de muitos cientistas da Europa para os EUA, sustentase que os estudantes devem aprender ciência no laboratório, não apenas memorizando o conteúdo do livro didático. Porém, quando a escola se tornou massificada, Dewey afirmou que a ciência deveria ser usada no cotidiano. Há o método científico que constitui em reunir evidências e chegar a uma conclusão. Contudo, foi questionado pelos cientistas se qualquer um poderia fazer ciência. Igualmente, um método simples não poderia dar conta de toda a complexidade e da diferença de objetos a que a ciência se dedica. $\mathrm{O}$ ensino da ciência foi controverso entre ensinar a ciência por um manual ou por experimentos laboratoriais - se deveria ser como um conjunto de conclusão ou fatos ou como um método de investigação. Método ou métodos. Um ensino de ciências para o ensino superior deveria valorizar a memorização ou o ensino do processo da ciência? A seguir, veremos as contribuições do educador J. J. Schwab sobre o assunto.

${ }^{3}$ A parcialidade de gênero na paleoantropologia, em French (2009, p. 137-152).
} 
reconstruída a posição de Kuhn, baseando-se, inteiramente, na Estrutura. Na terceira parte, são apresentadas as objeções feitas por Harvey Siegel à posição kuhniana a respeito dos manuais.

\section{ACERCA DOS TIPOS E DOS GÊNEROS TEXTUAIS: OS GÊNEROS CIENTÍFICOS}

Os linguistas têm estudado os tipos e os gêneros literários. Os gêneros literários são os produtos criativos da comunicação humana. Eles atendem às necessidades da comunicação humana. Os falantes estão sempre inovando-os e adequando-os às novas realidades e necessidades sociais. Gêneros textuais nascem, morrem e ressuscitam.

Há uma grande variedade de gêneros literários, como o poema, o conto, o diário, o resumo, a piada, a biografia, a receita de culinária, o manual de montagem de uma bicicleta, dentre muitos outros. Recentemente temos a inovação de novos gêneros textuais, que são usados no blog, no e-mail, no WhatsApp, no Twitter, no Youtube, no Facebook, dentre outros meios digitais.

Além dos gêneros textuais, os linguistas estudam também os tipos textuais. Esses são vistos como formas platônicas, eternas e puras. Essas formas constituem e são as fontes dos gêneros. Os gêneros textuais se utilizam e são formados por essas formas fixas, que são os tipos textuais.

Não há um consenso do número exato dos tipos textuais. Será seguida a divisão de cinco tipos textuais, a saber: a tipologia textual, que estuda os tipos de textos narrativo, dissertativo, descritivo, expositivo e injuntivo. O tipo injuntivo é encontrado, por exemplo, em uma receita de bolo ou num manual de ventilador, os demais tipos são bastante conhecidos por seus nomes.

Há gêneros mais especializados, os chamados gêneros científicos. Podemos dividi-los em dois tipos. Os intertextos - aqueles que se originam de outros textos - como fichamento, resumo, resenha, resumo expandido, dentre outras tipologias. Os textos científicos concernem ao projeto de pesquisa, à comunicação científica (oral ou escrita), ao artigo científico, ao relatório técnico-científico, aos trabalhos acadêmicos (monografia, dissertação e tese), ao ensaio, ao manual, dentre outras formas. $\mathrm{O}$ foco é o gênero textual do manual científico e sua importância na compreensão da ciência, como sustentado por Thomas Kuhn. 


\section{AS TESES DE THOMAS KUHN NA ESTRUTURA SOBRE O MANUAL CIENTÍFICO4}

Na Introdução da Estrutura, Kuhn (1975) sustenta que a reunião de fatos, teorias e métodos reunidos nos textos atuais fornecem uma imagem da ciência progressiva e cumulativa. Contudo, essa imagem não é o que acontece com a ciência, mas a imagem criada pelo paradigma vencedor. É uma reconstrução do vencedor da história daquela disciplina. Mostrar que é assim que acontece é um dos propósitos da Estrutura. Os livros-textos das disciplinas científicas não são uma fonte adequada para entender como funciona a ciência. Contudo, são materiais importantes para sustentar os argumentos de Kuhn a favor da sua compreensão do que de fato é a ciência (KUHN, 1975, 19-28).

No primeiro capítulo da Estrutura, Kuhn (1975, p. 29) sustenta que os manuais produzidos $^{5}$ na e para a ciência normal contêm uma ou mais realizações do passado, que fundamentam a prática da comunidade científica. No manual, essas realizações (paradigma) estão raramente na sua forma original. Segundo Kuhn:

Tais livros expõem o corpo da teoria aceita, ilustram muitas (ou todas) as suas aplicações bem sucedidas e comparam essas aplicações com observações e experiências exemplares. Uma vez que tais livros se tornaram populares no começo do século XIX (e mesmo mais recentemente, como no caso das ciências amadurecidas há pouco), muitos dos clássicos famosos da ciência desempenham uma função similar. (KUHN, 1975, p. 29-30).

Para Kuhn, os livros-textos ou manuais fornecem os problemas e o modo de solução deles. Da assimilação pelo ensino dos exemplares, os futuros cientistas guiam a sua prática científica. Um exemplo disso é resolver os problemas científicos pelos exemplares, estabelecendo analogias (KUHN, 1975, p. 30).

Para Kuhn, os livros-textos, quando comparados, começam a revelar as alterações paradigmáticas. Ele oferece o exemplo da luz que é definida como composta de fótons, mas que, há não muito tempo, os manuais definiam como movimento ondulatório transversal e, por sua vez, Newton como corpúsculos de matéria (KUHN, 1975, p. 32).

Quando um paradigma é constituído, ele provoca a criação de jornais especializados. Os cientistas já não precisam definir os termos e defendê-los. Isso é deixado para os criadores dos manuais. O cientista maduro localiza o seu trabalho nos aspectos mais esotéricos dos fenômenos

\footnotetext{
${ }^{4}$ As referências ao manual científico estão concentradas majoritariamente nos capítulos 01 e 10 e menos no 12.

${ }^{5}$ Manuais citados por Kuhn: A física de Aristóteles, o Almagesto de Ptolomeu, Principia e a Óptica de Newton, a Eletricidade de Franklin, a Química de Lavoiser e a Geologia de Lyell (KUHN, 1975, p. 30).
} 
do campo de estudo, para além do que já está depositado nos manuais. Esses estudos apareceram em textos breves, dirigidos aos seus colegas de profissão e não ao grande público, como a Origem das espécies. Esses estudos exigem o domínio do paradigma (KUHN, 1975, p. 40).

Antes que o paradigma esteja estabelecido à criação do manual é tido como criativo e fruto de pesquisa; porém, depois de o paradigma estar posto, o manual não é mais digno de atenção. Kuhn afirma que: "O cientista que escreve um livro [um manual científico] tem mais probabilidades de ver sua reputação comprometida do que aumentada.” (KUHN, 1975, p. 40). Após o paradigma estar fixado, os textos científicos se tornam incompreensíveis para os leigos. Isso já era assim na Antiguidade e é muito mais nos nossos dias. A ciência é uma atividade especializada e esotérica (KUHN, 1975, p. 41).

Podemos inferir que dada a natureza da ciência como descrita por Kuhn, um leigo não terá acesso à ciência por um manual e, muito menos, pelos artigos científicos. Eles não são completamente inteligíveis para o leitor leigo (pelo menos das ciências como a física ou a química). A compreensão dos manuais e artigos científicos demanda algo além deles próprios para serem compreendidos.

Uma parte da produção científica dos cientistas é a busca por refinar os fatos pelas observações, que exigem a criação de maquinário complexo e caro. Muitos cientistas fizeram fama pela sua competência em informar fatos com precisão, segurança e o alcance das modificações nas medições anteriores (KUHN, 1975, p. 46).

A literatura científica profissional do paradigma, que aparece nas revistas especializadas, para Kuhn, esgota-se na determinação do fato significativo, na harmonização dos fatos com a teoria, na articulação da teoria e nos problemas extraordinários, que aparecem com os avanços do paradigma (KUHN, 1975, p. 55).

Kuhn sustenta que o paradigma vem na forma de ilustrações recorrentes nas suas aplicações conceituais, instrumentais e na observação. Essas ilustrações são reveladas nos manuais, conferências e exercícios de laboratório. Ele ressalta que "ao estudá-los e utilizá-los na prática, os membros da comunidade considerada aprendem seu ofício" (KUHN, 1975, p. 67$68)$.

Os paradigmas geram regras, que servem para orientar o cientista nos seus estudos, mas o paradigma não é um conjunto de regras; é algo mais difuso. Para explicar isso, Kuhn cita o famoso Personal Knowledge de Polanyi: 
[Michael Polanyi] desenvolveu brilhantemente um tema muito similar, argumentando que muito do sucesso do cientista depende do "conhecimento tácito", isto é, do conhecimento adquirido através da prática e que não pode ser articulado explicitamente. (POLANYI, 1958, apud KUHN 1975, p. 69).

Pela educação e literatura a que os postulantes e cientistas são expostos, eles analogicamente vão identificando tacitamente os problemas e o modo de solução. Não há um sistema de regras que os guia na busca de problemas e soluções. É semelhante ao aprendizado de uma língua, não há consciência completa das regras sintáticas, semânticas e pragmáticas envolvidas no desempenho linguístico.

A aprendizagem da ciência nunca é apenas teórica e abstrata, prescindindo da sua aplicação. Os manuais sempre são holísticos, no sentido em que os conceitos, as leis e as teorias são compreendidas por exemplos das aplicações. Kuhn (1975, p. 71-72, grifo nosso) deixa bem claro esse ponto:

\footnotetext{
As aplicações não estão lá simplesmente como um adorno ou mesmo como documentação. Ao contrário, o processo de aprendizado de uma teoria depende do estudo das aplicações, incluindo-se aí a prática na resolução de problemas, seja com lápis e papel, seja com instrumentos num laboratório. Se, por exemplo, o estudioso da dinâmica newtoniana descobrir o significado de termos como "força", "massa", "espaço" e "tempo", será menos porque utilizou as definições incompletas (embora algumas vezes úteis) do seu manual, do que por ter observado e participado da aplicação desses conceitos à resolução de problemas.
}

Desse modo, aprende-se por exemplares que aquela área fornece à formação do postulante a cientista. $\mathrm{O}$ cientista se torna competente na solução dos problemas do paradigma. Não há a necessidade de métodos, de problemas e de padrões de soluções conscientemente, seguidos por um conjunto de regras. Kuhn, semelhante a Polanyi, não acredita que mesmo um cientista deveras competente consiga explicitar um conjunto de regras necessárias e suficientes para guiar a sua ação.

Kuhn (1975) chega a sustentar que cientistas da mesma área ou muito próxima que utilizam o mesmo manual e as mesmas realizações científicas podem adquirir paradigmas bastante diferentes no curso dos seus estudos de especialização. Kuhn exemplifica isso com o caso da mecânica quântica. Mesmo que todos sejam físicos, o significado da mecânica quântica será diferente para alguém ocupado em Física dos estados sólidos ou para a Química. Kuhn (1975, p. 75) afirma que "o significado que a Mecânica Quântica possui para cada um deles depende dos cursos frequentados, dos textos lidos e dos periódicos estudados". 
Um aspecto importante para Kuhn na Estrutura é o treinamento da percepção do postulante a cientista. Há um treinamento para ver a natureza, de certa maneira. A orientação é dada pelo paradigma vigente. O estudante tem que formar a Gestalt correta para tornar-se um cientista competente. Gradualmente, o estudante é ensinado a ver uma fotografia da câmara de Wilson, de linhas confusas passa a ver eventos subnucleares (KUHN, 1975, p. 146). A tese é que a observação é afetada pelo background teórico do cientista. Existe uma contaminação teórica durante o processo de observação. Há uma relação entre o objeto percebido e a teoria; ver isso ou aquilo depende de treinamento e não de simples observação e de uma intepretação oferecida pelo manual.

A compreensão cumulativa de que a ciência não passa por revoluções, por rupturas é devido à fonte autoritária dos elaboradores dos manuais científicos, que disfarçam essas revoluções. Essa fonte de autoridade está presente em "três gêneros", sobretudo nos manuais científicos, como nos textos de divulgação e obras filosóficas inspiradas nos dois gêneros anteriores. Kuhn (1975, p. 174) está se referindo à análise lógica do conhecimento científico feita pelos positivistas lógicos.

Esses três gêneros apenas refletem a ciência normal estabelecida. Numa troca de paradigmas, os manuais têm que ser reescritos com os seus novos problemas e soluções. Apenas cientistas vivos entre um paradigma e outro conseguem ter consciência da mudança, enquanto a maioria confia no manual e na sua versão de como as coisas se desenvolveram na ciência, de uma forma cumulativa, eliminando alguns erros e anexando novas descobertas (KUHN, 1975, p. 175).

Os manuais conseguem esse resultado, pois recortam a história daquela disciplina, de acordo com aquilo que se encaixa no paradigma vigente. São estabelecidos elos que vêm do início de uma tradição bastante antiga. Constrói-se, assim, um resumo da disciplina científica, dando a impressão de continuidade (KUHN, 1975).

Na elaboração dos manuais, não há apenas a seleção do que interessa, mas “em parte distorção". Essa reelaboração aparenta uma tradição focada nos mesmos problemas, soluções, métodos, dentre outros aspectos. O desprezo da história faz parte, segundo Kuhn (1975, p. 176), da ideologia da profissão científica.

Os próprios cientistas, como Newton e Dalton quando descrevem o seu próprio trabalho e comparam com o anterior, tendem a ver linearidade. Eles distorcem os antepassados, iludindose sobre as profundas diferenças entre eles (KUHN, 1975, p. 177). 
Essas reconstruções estão cheias de anacronismos. Um exemplo que Kuhn oferece da distorção é o caso de Robert Boyle, do século XVII. Ele escreveu o famoso The Sceptical Chymist (1661). Os manuais sustentam que ele oferece uma definição do que seja um "elemento químico”. Não obstante, Boyle não acreditava que existia tal coisa (KUHN, 1975, p. 179-180).

Há, também, a possibilidade da ilusão, segundo Kuhn. Termos como "elemento", "espaço", "tempo", "planeta", "satélite”, dentre outros aspectos, são muito antigos. Todavia, o significado e a referência deles são diferentes. Esses termos sofreram profundas alterações nas várias teorias científicas, que foram sendo estabelecidas durante a história da ciência e das disciplinas científicas. Muitos termos continuam sendo usados nos manuais e nos artigos científicos, mas o significado e a referência mudaram durante as revoluções da ciência. Não obstante, podem dar a impressão de continuidade histórica. Kuhn (1975, p. 180) ressalta que “[...] nem Einstein teve que inventar ou mesmo redefinir explicitamente 'espaço' e 'tempo', a fim de dar a esses conceitos novos significados no contexto de sua obra”.

Outro aspecto, para Kuhn, é que a reconstruções dos manuais dão a impressão de que o desenvolvimento linear da ciência é feito por indivíduos. A ciência não é construída de forma individualista, mas sim comunitária. Para ele, não se compreende a ciência por uma abordagem individualista. Essa concepção comunitária da ciência é um dos aspectos fundamentais da perspectiva kuhuniana do que seja a ciência (KUHN, 1975, p. 178).

Os manuais dão a impressão de que a atividade científica se desenvolve com um conjunto atemporal de problemas e soluções, que são arduamente conquistados por cientistas individuais e alguns considerados pais ou heróis da ciência.

A função do manual nas ciências é diferente do manual na Música, nas Artes Gráficas ou na Literatura. O artista aprende sendo exposto aos trabalhos de outros artistas, de modo especial os do passado. Frequentemente, os manuais têm apenas uma função secundária (KUHN, 1975, p. 207).

Na História e nas Ciências Sociais, o manual já adquire uma importância maior. Não obstante, há leituras das fontes primárias, como as obras de Weber, de Marx, de Comte, de Durkheim, dentre outros autores. O aluno é exposto à profusão e à diversidade da sua área. $\mathrm{A}$ avaliação de tudo isso será feita pelo próprio estudante (KUHN, 1975, p. 207).

Isso é diferente com os estudantes das ciências da natureza, uma vez que os manuais serão os únicos guias até o jovem cientista começar a própria pesquisa. Artigos e monografias ficam restritos aos alunos dos cursos mais avançados (KUHN, 1975, p. 207). Porém, o autor reconhece que essa restrição é eficaz, dados os objetivos da ciência normal. O discente 
rapidamente aprende o que é importante para a sua profissão. Kuhn (1975, p. 208) afirma que: "Trata-se certamente de uma educação rígida e estreita, mais do que qualquer outra, provavelmente - com a possível exceção da teologia ortodoxa."

Quando a comunidade científica repudia um paradigma, ela também renuncia a grande parte da sua literatura. Kuhn (1975, p. 200) evidencia que "a educação científica não possui algo equivalente ao museu de arte ou à biblioteca de clássicos". Isso cria a ilusão de que a história da disciplina é um caminho linear de acúmulo, desenvolvimento e progresso. Os estudantes das ciências, quando em contato com a história da disciplina, têm dificuldades de entender uma ciência mais antiga a partir dos seus pressupostos (KUHN, 1975, p. 209).

A comunidade científica é formada por praticantes de uma especialidade científica e educada com os mesmos manuais. A comunidade científica é submetida a uma educação uniforme, que não é percebida nas outras disciplinas, mesmo tendo a mesma literatura e as mesmas lições. Há uma padronização na literatura (KUHN, 1975, p. 220). O autor ressalta que "o conhecimento científico, como a linguagem, é intrinsecamente a propriedade comum de um grupo ou então não é nada. Para entendê-lo, precisamos conhecer as características essenciais dos grupos que o criam e o utilizam" (KUHN, 1975, p. 257).

Rastreando a Estrutura, foram observados pelo menos dezesseis funções a respeito dos manuais científicos, como desenvolvido nos parágrafos acima, que serão aqui brevemente evidenciados: a) os manuais são fonte de autoridade para os neófitos; b) definem quais são os problemas científicos; c) definem o tipo ideal de solução científica; d) os exemplares não são ou raramente estão na forma original dos seus primeiros inventores; e) os manuais não oferecem um conjunto de regras suficientes para a solução dos problemas, nem para a limitação de quais são os problemas; f) os manuais oferecem uma imagem progressiva e acumulativa da ciência; g) os manuais são reconstruídos sempre após uma revolução científica na forma de um progresso quase linear. Eles apagam as transformações abruptas da ciência; h) os manuais não são uma fonte para conhecer a história real das ciências (eles "mentem"); i) comparando os manuais de várias épocas começamos a perceber as suas diferenças e as mudanças (revoluções); j) os manuais são importantes, mas a aprendizagem da ciência vai além deles, como na vivência no laboratório e na resolução dos exercícios. Muito do que se aprende, se aprende tacitamente; k) nos manuais os exemplos são holísticos. Há uma articulação entre os conceitos, os temas e as leis. São sempre compreendidos por exemplos e da sua aplicação; 1) o mesmo manual pode formar profissionais de disciplinas diferentes. O entendimento do mesmo assunto pode divergir profundamente entre áreas diferentes; m) a invisibilidade das rupturas da ciência é dada em 
"três gêneros", sobretudo no manual científico, nos textos de divulgação e nas obras de filosofia da ciência (positivismo lógico); n) há uma "ideologia do progresso" na ciência. Os cientistas forçam (por exemplo, Newton e Galileu) e se esforçam para que os seus resultados estejam intimamente ligados à tradição; o) os manuais científicos são muito diferentes do material didático de outras áreas como a Música, as Artes Gráficas, a Literatura, a História, Sociologia e a Filosofia. Nessas disciplinas, a divergência e a pluralidade são as notas principais e p) a comunidade científica é educada pelos mesmos manuais. Há uma unidade nos problemas e soluções. A educação é muito uniforme comparada às outras disciplinas.

A compreensão kuhniana de ciência e das funções do manual científico receberam inúmeras críticas. Vejamos uma das primeiras críticas dirigida a essas funções dos manuais feita por Harvey Siegel.

\section{A CRÍTICA DE HARVEY SIEGEL À VISÃO DE KUHN EM RELAÇÃO À EDUCAÇÃO CIENTÍFICA E AO USO DO MANUAL}

O manual científico, segundo a Estrutura, ensina exemplares (problemas e soluções ideais); esconde rupturas (revoluções); dá a impressão de um crescimento linear (progresso); é fonte de autoridade, semelhante ao manual de Teologia; forma uma comunidade muito unânime na forma de pensar, agir e ver o mundo; passa a impressão de estar ligado a uma antiga tradição científica. Acerca da natureza da ciência, o manual científico mente. São formados cientistas não críticos, mas sujeitos cheios de fé no paradigma (ciência normal) e fechados a mudanças (conservadores). Essa visão certamente não se adequa à concepção iluminista de ciência como objetiva e crítica.

Harvey Siegel (1997) é um defensor de uma concepção crítica de educação. Para ele, o objetivo da educação é formar estudantes com um pensamento crítico. Possuir um pensamento crítico é ser alguém apropriadamente movido por razões.

São muito conhecidas as muitas críticas que foram dirigidas à Estrutura, desde a sua publicação (SCHEFFLER, 1967; LAKATOS; MUSGRAVE, 1979). Esse foi um livro que foi aplaudido por muitos, mas muito criticado por outros. De fato, a imagem que forneceu à comunidade científica e ao ensino da ciência não foi aquela que filósofos e cientistas compartilhavam naquela época e nem mesmo nos dias de hoje.

O filósofo da educação Harvey Siegel, no seu artigo "Kuhn and Schwab on Science Texts and the Goals of Science Education" (1978), no capítulo oitavo de Education Reason (1998), trata diretamente do tema do manual científico em Kuhn após a publicação da 
Estrutura $^{6}$. Segundo Siegel (1978), os cientistas devem ser formados como agentes críticos, não seguidores cegos do paradigma científico dominante como descreve Kuhn na Estrutura. Para sustentar a sua crítica, Siegel se apoia nas conclusões do filósofo da educação científica Joseph J. Schwab ${ }^{7}$.

Joseph J. Schwab, em 1962, lança o texto "The Teaching of Science as Enquiry", que sustenta uma concepção de ciência muito semelhante à Estrutura de Kuhn. Contudo, o autor argumenta que o cientista deve focar-se na "ciência fluida" (ciência revolucionária) e não na "ciência estável" (ciência normal).

Schwab foca na ciência fluida, que considera o aspecto mais importante da prática científica. A ciência é uma prática progressista, não conservadora. Ela não deve sê-la. Segundo ele, é isso que tem acontecido cada vez mais à ciência contemporânea. Essa visão é adequada à natureza o ao desenvolvimento da ciência contemporânea. Ele ridiculariza o dogma da ciência estável, critica a tensão entre a ciência fluida e os manuais. Eles são ensinados frequentemente, de modo a transmitir como um conteúdo empírico, literal e de verdades irrevogáveis. Porém, para Schwab, isso não serve como um ideal para uma educação científica correta.

Para Schwab, o ensino de ciências deve levar os alunos a ser competentes cientistas fluidos e não alunos dóceis ao manual ou ao professor. O manual deve ser objeto de desafio e de superação e não de adestramento. O professor não serve apenas para esclarecer o manual, mas desenvolver habilidades para que o aluno possa aprender por si.

Siegel concorda com Schwab, tanto com a construção histórica da ciência, bem como com a prescrição acerca do ensino das ciências de Schwab. O dever do professor de ciências é promover uma educação científica crítica, buscando a inovação e o questionamento rigoroso do estabelecido (o ensino). A ciência deve ser uma atividade eminentemente crítica, segundo Siegel.

Segundo a leitura de Siegel (1978), Kuhn está apenas descrevendo o funcionamento da ciência e dos manuais na Estrutura. O autor analisa a ciência, utilizando-se de ciências, seja a

\footnotetext{
${ }^{6}$ Não encontramos nenhum outro artigo tratando do tema ou capítulo de livro dedicado exclusivamente ao manual na Estrutura além dos textos de Siegel.

${ }^{7}$ Joseph J. Schwab (1909-1988) foi um educador americano. Ele nasceu em Columbus, no Mississipi, começou a ensinar na Universidade de Chicago em 1936 e lecionava educação e ciências naturais. Ele enfatizou o estudo da filosofia da educação e da ciência na preparação dos currículos. Schwab criou um programa chamado Pratical para auxiliar melhorias na educação. Seus livros incluem Eros and Education (1958), The Teaching of Science as Enquiry (1962), Education and the Structure of the Disciplines (1961), College Curriculum and Student Protest (1969), and Science, Curriculum, and Liberal Education: Selected Essays (1978). (ENCYCLOPEDIA.COM, c2019; EDUCATION ENCYCLOPEDIA, c2019).

${ }^{8}$ Coincidentemente, o texto de Schwab é lançado no mesmo ano da Estrutura. Não tenho informação se Schwab e Kuhn tiveram algum contato pessoal ou conheciam o trabalho um do outro.
}

Sapere aude - Belo Horizonte, v. 12 - n. 23, p. 160-173, Jan./Jun. 2021 - ISSN: 2177-6342 
história, a psicologia bem como as sugestões de filósofos. Porém, o autor suspeita que Kuhn apoie essa visão conservadora de ciência.

Mesmo que a visão de Schwab seja muito semelhante à abordagem de Kuhn em alguns aspectos, há, porém, diferenças profundas. A ciência só é possível por ela formar um paradigma e estabelecer uma comunidade científica aficionada e cheia de esperança de resolver os problemas do campo científico pelo paradigma vigente. Segundo Kuhn, um ensino focado na ciência revolucionária (fluida) não possibilitaria o necessário esforço, paciência e tempo para desenvolver o paradigma. Se Schawb estiver correto, Kuhn está profundamente equivocado na sua descrição sobre como funciona a ciência. Nesse ponto, Schawb está muito próximo da visão do racionalismo crítico em sua fase ingênua como criticada por Lakatos e abandonada por Popper. Ademais, Schawb está focado na ciência contemporânea, e o seu objetivo é normativo, não descritivo como o de Kuhn.

Por outro lado, se Kuhn estiver correto, há algo de muito amargo para se admitir: ser a ciência uma atividade não pautada pela crítica e pela tentativa de superar o status quo científico, mas concentrada na inculcação do paradigma vigente. Deve-se estar muito próximo de certo conceito de religião - pelo menos em características formais — baseado na fé, na esperança e na autoridade.

Schawb e Siegel não querem apenas descrever a ciência, mas também prescrever. Os autores sustentam que a descrição da ciência corrobora a prescrição de como deve ser o ensino da ciência. Contudo, eles não negam o desvirtuamento que possa acontecer durante o ensino mal feito das ciências, mas que deve ser superado por uma educação eminentemente crítica. Um aspecto ressaltado por Schwab e Siegel é a atitude do professor de focar nas transformações da ciência, na ciência que busca superar-se.

Contudo, Kuhn tem razão em defender que os principiantes em ciência têm mínimas capacidade para criticar o paradigma existente. Kuhn (1975, p. 111) afirma que “[...] os estudantes de ciência aceitam as teorias por causa da autoridade do professor e dos textos e não devido às provas. Que alternativas, que competência possuem eles?". Tem que haver certa docilidade em apreender o paradigma vigente. Uma atitude extremamente crítica prejudica o aprendizado do que quer que seja. A crítica quase sempre se segue depois que compreendemos e assimilamos determinada teoria. Parece-nos que a atitude de crítica e o estímulo à crítica têm que vir incentivada pelo próprio professor de ciências. Ele deve auxiliar o estudante a desenvolver esse hábito e desenvolver as competências para uma crítica racional. Bem como auxiliar o estudante a compreender o empreendimento científico como falível e no máximo 
confiável. E que certeza, verdade e semelhantes podem ser apenas ideias reguladoras e não realidades alcançadas. É no esforço de alcançar essas excelências que a ciência adquire sua confiabilidade, justificação e autoridade.

Uma das soluções encontradas para amenizar o problema foi colocar na grade curricular da formação do cientista as disciplinas de filosofia, história da ciência, CTS (Ciência, Tecnologia e Sociedade) ou semelhantes. Essas disciplinas seriam muito úteis para o aluno evitar cair em uma concepção dogmática e irreal de ciência, mostrando os grandes desafios epistemológicos, metafísicos, éticos que as teorias e a atividade científica suscitam, bem como o caráter falível do conhecimento científico. Na reforma dos currículos dos cursos, há sempre a tentação de retirar ou não colocar essas disciplinas reflexivas e substituí-las por disciplinas consideradas mais úteis para o futuro profissional. Uma compreensão baseada numa racionalidade puramente instrumental da ciência nos leva a problemas epistemológicos como o dogmatismo, e a sociais como a dissolução de tudo o que não é econômica ou tecnologicamente viável.

\section{CONSIDERAÇÕES FINAIS}

Como vimos, o gênero científico do manual é considerado importante para Kuhn para compreendermos a natureza da ciência. Porém, ele também é limitado, pois a ciência é compreendida e aprendida na prática junto a cientistas maduros, que são imitados pelos seus alunos. Siegel e Schwab criticam a visão conservadora e dogmática de ciência descrita por Kuhn. Schwab tem uma visão inversa à de Kuhn, mesmo que muito semelhante em alguns aspectos. É inversa no sentido de colocar o foco na ciência revolucionária e não na ciência normal ou na sua terminologia; na ciência fluida e não na ciência estável. Schwab se centra na ciência dos nossos dias e não na ciência do passado. O foco é a importância do espírito crítico no ensino e na aprendizagem da ciência. Para Siegel, a ciência não pode ser adestramento. Siegel e Schwab enfatizam a atitude crítica do professor de ciência.

Apontamos que o ensino de disciplinas como a História da Ciência, a Filosofia da Ciência e semelhantes foram incluídos nos currículos científicos para fazer parte da formação do cientista e, assim, enfraquecer o ensino dogmático da ciência. Kuhn pode estar certo em sua reconstrução histórica, mas Siegel e Schwab podem estar certos na possibilidade de superar o dogmatismo. Porém, estará Kuhn certo de que uma ciência sem fé paradigmática não funcionará? 


\section{REFERÊNCIAS}

EDUCATION ENCYCLOPEDIA. c2019. Disponível em:

https://education.stateuniversity.com/pages/2401/Schwab-Joseph-1909-1988.html. Acesso em: 29 out. 2020.

ENCYCLOPEDIA.COM. c2019. Disponível em:

https://www.encyclopedia.com/religion/encyclopedias-almanacs-transcripts-andmaps/schwab-joseph-j. Acesso em: 29 out. 2020.

FLECK, Ludwik. Gênese e desenvolvimento de um fato científico. Belo Horizonte: Fabrefactum, 2009.

FRENCH, Steven. Filosofia da Ciência: Conceitos-chaves. Porto Alegre: Artes Médicas, 2009.

KUHN, Thomas, S. A estrutura das revoluções científicas. São Paulo: Perspectiva, 1975.

KUHN, Thomas, S. Foreword. In: FLECK, L. Genesis and Development of a Scientific Fact. Chicago: The University of Chicago Press, 1979. p. 7 a 11.

LAKATOS, I.; MUSGRAVE, A. A crítica e o desenvolvimento do conhecimento. São Paulo: EDUSP, 1979.

RUDOLPH, John L. How we Teach Science: What's Change, and Why it Matters.

Cambridge: Harvard University Press, 2019.

SCHEFFLER, Israel. Science and Subjectivity. New York: Bobbs-Merrill, 1967.

SCHWAB, J. J. The Teaching of Science as Enquiry. In SACWAB, J. J.; BRANDWEIN, P. F. The Teaching of Science. Local: Harvard University Press, 1962. Disponível em: https://archive.org/details/teachingofscienc0000jose/page/n5/mode/2up?q=The+Teaching+of +Science+as+Enquiry. Acesso em: 05 jul. 2020.

SIEGEL, Harvey. Educating Reason: Rationality, Critical Thinking and Education. New York: Routledge, 1998.

SIEGEL, Harvey. Rationality Reddemed? Further Dailogues on an Education Ideal. New York: Routledge, 1997.

SIEGEL, Harvey. Kuhn and Schwab on Science Texts and the Goals of Science Education. Educational Theory, Local, v. 28, n. 4, p. 302-309, Fall 1978. 